\title{
QUEBRA DA CONFIANÇA E APLICAÇÃO DA RESPONSABILIDADE CIVIL NAS RELAÇÕES PRÉ-CONTRATUAIS NOS MEIOS ELETRÔNICOS DE NEGOCIAÇÃO
}

\author{
Bárbara Ferreira De Bonis ${ }^{1}$ \\ Irineu Francisco Barreto Junior ${ }^{2}$
}

\section{RESUMO}

A relação que antecede a formalização de um contrato é denominada de fase pré-contratual realizada entre duas ou mais partes no âmbito civil. O presente artigo visa analisar as relações de consumo na fase pré-contratual dos contratos eletrônicos pactuados, diante da vinculação das fases de negociação e do modus operandi da parte contrária em consolidar o negócio e da violação dessa conduta. Analisa o efeito da ruptura abrupta da fase pré-contratual em razão da alteração de conduta da parte, bem como as consequências da quebra da teoria da confiança com a parte lesada e incidência da aplicação da responsabilidade civil.

Palavras-chave: Contratos; Responsabilidade Civil; Contratos Eletrônicos; Teoria da Confiança; Sociedade da Informação.

\section{THE BREAK OF CONFIDENCE AND THE APPLICATION OF CIVIL RESPONSIBILITY IN THE PRE CONTRACTUAL RELATIONS IN ELECTRONIC MEANS OF TRADING}

\begin{abstract}
The relationship that precedes the formalization of a contract is called a pre-contractual phase in the civil law. The purpose of this article is to analyze the relations of consumption in the pre-contractual phase of the agreed electronic contracts, due to the linkage of the negotiation phases and the modus operandi of the opposing agent in consolidating the business and the violation of this conduct. It analyzes the effect of the abrupt rupture of the pre-contractual phase due to the change in the conduct of an involved, as well as the consequences of the breakdown of the trust theory.
\end{abstract}

Keywords: Contracts; Civil Responsibility; Electronic Contracts; Theory of Trust; Information Society.

\section{Introdução}

\footnotetext{
${ }^{1}$ Mestranda em Direito da Sociedade da Informação pelo Centro Universitário das Faculdades Metropolitanas Unidas (FMU-SP). Especialista em Direito Civil Lato Sensu pela Universidade Presbiteriana Mackenzie. Advogada. São Paulo, SP, Brasil. barbarabonis@ gmail.com

${ }^{2}$ Pós Doutorando em Sociologia pela USP. Doutor em Ciências Sociais pela PUC-SP. Docente do Programa de Mestrado em Direito da Sociedade da Informação FMU-SP. Analista de Pesquisas da Fundação Seade. São Paulo-SP, Brasil.neubarreto@hotmail.com
} 
O presente artigo possui a finalidade inicial de analisar a conceituação das tratativas iniciadas antes da consolidação ou formalização das relações contratuais no âmbito digital. Como é cediço o desenvolvimento tecnológico proporcionou a criação do ambiente on-line viabilizando a existência de uma nova sociedade conectada à internet ou ao ciberespaço. Desta forma, observa-se uma nova era com o surgimento da Sociedade da Informação, por se tratar de uma sociedade calcada em bens imateriais e com tecnologias que são essencialmente de cunho intelectual, uma verdadeira reviravolta científica e tecnológica.

Nessa linha de raciocínio, os indivíduos alteraram seus hábitos cotidianos de contratação, que inicialmente ocorriam apenas de forma física, utilizando, assim, a internet como meio maciço negocial. Evidentemente que a alteração de hábito trouxe novas vertentes à temática da pré-contratação no âmbito digital, tendo em vista os preceitos basilares nele arraigados, bem como a estrutura sui generis do método de contratação. Nesse sentido, cabe ao Direito acompanhar tais mudanças e transformações, juridicamente e doutrinariamente, com o intuito de assegurar a plena efetivação de direitos e deveres que abrangem os conflitos existentes neste novo padrão de sociedade.

No presente artigo serão analisadas as relações consumeristas pactuadas, ou seja, o que se denomina por Business to Consumer (B2C), que se trata das relações conduzidas diretamente entre as companhias/empresas e os consumidores que são os usuários finais dos produtos e serviços.

Ressalta-se que em caso de quebra da legítima expectativa expressada pela parte contratante (consumidor) em relação a conduta do outro contratante (companhias/empresas) no vínculo contratual a ser consolidado, tal conduta enseja a responsabilidade civil, inclusive, utilizando-se como salvaguarda o Código de Defesa do Consumidor.

Por derradeiro, a metodologia de pesquisa aplicada se baseia na interpretação sistemática normatiza por meio do conjunto de princípios e sistemas normativos jurídicos das relações contratuais, os quais possuem a finalidade de nortear as tratativas de consumo, nas relações pré-contratuais conduzidas pelas partes na concretização do possível pacto contratual.

O escopo epistemológico do estudo adota a linha jurídico-dogmática que considera o direito com autossuficiência metodológica e trabalha com os elementos internos ao ordenamento jurídico. Essa abordagem desenvolve investigações com vistas à compreensão 
das relações normativas nos vários campos do direito e com a avaliação das estruturas interiores ao ordenamento jurídico. Concomitantemente acentua a noção de eficiência e eficácia das relações entre e nos institutos jurídicos restringindo a análise do discurso normativo aos limites do ordenamento. Isto não significa que deve estar voltado apenas para o interior do ordenamento ou ali enclausurado (GUSTIN; DIAS, 2006).

Aborda ainda a linha investigativa Jurídico Sociológica que se propõe a compreender o fenômeno jurídico no ambiente social mais amplo. Para tal, analisa o direito como variável dependente da sociedade e trabalha com as noções de eficiência, eficácia e efetividade das relações entre direito e sociedade. Preocupa-se com a facticidade do Direito e com as relações contraditórias que estabelece com o próprio Direito e com os demais campos: sociocultural, político e antropológico (GUSTIN; DIAS, 2006). Por fim, estuda a realização concreta de objetivos propostos pela lei, por regulamentos de todas as ordens e de política públicas e sociais.

\section{Conceito de Pré-Contrato}

Vivemos uma nova era marcada pela revolução tecnológica ocorrida nos meios de comunicação que, desde meados da década de 1990, deu origem a uma nova era denominada como Sociedade da Informação. A sua principal característica é a geração e propagação de informações, advindas de qualquer lugar do mundo, em tempo quase que real e de forma inédita na história da tecnologia (BARRETO JUNIOR, 2015, p. 100-127.). Denota-se que a informação é o centro gravitacional desta nova era ou, em outras palavras, é possível afirmar que ela possui valor comercial. Nesse novo estágio de desenvolvimento econômico, as relações negociais adquirem nova roupagem e provocam a necessidade de acomodação das relações jurídicas ao ambiente informático.

Para o autor, "com a crescente adesão ao uso da Internet, têm-se desenvolvido uma sensação ainda difusa, entre os seus usuários, de que não existe qualquer possibilidade de sigilo, privacidade e intimidade on-line". Mais do que isso, o uso da rede oferece informações para um movimento em sentido reverso, no qual anúncios de produtos e ofertas de mercadorias em websites, mensagens recebidas por correio eletrônico, pop-ups e várias outras comunicações publicitárias que o usuário recebe, são orientadas pelo uso que ele próprio faz da Internet. (BARRETO JUNIOR, 2015, p.130). 
Com o intuito de compreensão dessa acurada complexidade negocial na sociedade on-line, cumpre-se ressaltar, inicialmente, que a conceituação do instituto do pré-contrato não pode ser taxada como contratual, posto que não há um termo contratual firmado, bem como não é conveniente denomina-lo como extracontratual. Nesse sentido, conceitua Roberto Senise Lisboa:

\footnotetext{
A aproximação entre as pessoas que tem interesse na conclusão de um contrato se dá por meio das chamadas negociações preliminares, que buscam estabelecer os pontos convergentes para a formação do contrato. Ainda não há contrato no sentido jurídico, porém revela-se na conduta das partes a intenção de chegarem a um acordo de vontades com a finalidade de constituição, modificação ou extinção dos direitos. (LISBOA, 2010, p. 212.)
}

A referida fase se apresenta como um início de negociação entre os contratantes, o que pode ser denominado como tratativas iniciais, o qual derivam deveres específicos entre as partes e que antecede a consolidação do pacto contratual e sua posterior formalização. Como é cediço a responsabilidade contratual não se restringe apenas a formalização do contratual em si, possuindo viés amplo, abarcando a fase pré-contratual, contratual e pós-contratual. Nessa linha, as partes possuem o que se denomina de obrigações acessórias ou deveres anexos ao contrato, ou seja, deveres gerais de conduta na relação contratual em suas fases.

Nas relações de consumo o viés da responsabilidade quanto as fases contratuais entre fornecedor e consumidor é expresso e cristalino. Cumpre colacionar o entendimento da Claudia Lima Marques:

\footnotetext{
Na visão tradicional, o empresário ou seu preposto prestaria várias informações para o consumidor sobre o produto a ser adquirido, sobre as formas de pagamentos, os eventuais acréscimos, juros, frete etc., mas estariam as partes agindo na fase précontratual, preliminar de negociações, e, portanto, não vinculativa. Agora o CDC amplia a nocão de oferta no art. 30, inclui todas as informacões suficientemente precisas, mas, principalmente, regula a fase pré-negocial no art. 48 do Código (...) (g.n.) (MARQUES,1999, p.122)
}

Nessa linha, nota-se que com o advento do Código de Defesa do Consumidor, ocorreu a ampliação do entendimento vinculativo da fase pré-contratual entre as partes, inclusive, expressamente mencionado na noção de oferta inserida no artigo 30 e sua regulação elencada no artigo 48 ambos do Código de Defesa do Consumidor, in verbis: 


\section{QUEBRA DA CONFIANÇA E APLICAÇÃO DA RESPONSABILIDADE CIVIL NAS RELAÇÕES PRÉ- \\ CONTRATUAIS NOS MEIOS ELETRÔNICOS DE NEGOCIAÇÃO}

Art. 30. Toda informação ou publicidade, suficientemente precisa, veiculada por qualquer forma ou meio de comunicação com relação a produtos e serviços oferecidos ou apresentados, obriga o fornecedor que a fizer veicular ou dela se utilizar e integra o contrato que vier a ser celebrado. (g.n.)

Art. 48. As declaracões de vontade constantes de escritos particulares, recibos e pré-contratos relativos às relacões de consumo vinculam o fornecedor, ensejando inclusive execução específica, nos termos do art. 84 e parágrafos. (g.n.)

Isto posto, no momento das tratativas se opera a vinculação de responsabilidade daquele que oferece o produto ou serviço por meio das informações prestadas, quais sejam, transparência das informações, oferta, publicidade, preço, forma de pagamento, garantia, funcionamento do produto ou serviço e os termos que serão utilizados na formalização do contrato. Corroborando a argumentação, no voto do Ministro Fontes de Alencar ao se referir ao artigo 48 do CDC preleciona que "o espírito da lei é no sentido de que essas declarações, ou esses pré-contratos, vinculam aquele que assume o compromisso". (MARQUES,1999, p.128)

Desta forma, a alteração da conduta da parte contraria acarreta prejuízo a parte lesada, tendo em vista que esta construiu legitima expectativa na tratativa inicialmente estruturada, assim como também enseja a parte lesada a perda de outras oportunidades sobre a mesma negociação com contratantes diversos.

Conclui-se que a mudança abrupta na conduta de uma das partes que acarreta a não consolidação do contrato ou da contratação tem a possibilidade de ensejar a responsabilidade pré-contratual.

\section{Aplicação do pré-contrato nos meios de negociação eletrônica}

Nas relações que se desenvolvem no âmbito virtual, observa-se o acrescente interesse econômico do usuário para aquisição de bens e serviços ofertados no meio eletrônico fomentando o comercio eletrônico, o que se denomina na atualidade como e-commerce no modelo B2C (business to consumer).

Isto posto, diante da evolução das negociações entre consumidor e fornecedor no âmbito digital, se faz necessário a análise do instituto do pré-contrato nas plataformas e sites on line, no qual promovem a aquisição de diversos bens de consumo e serviços. Nesse sentido, cumpre colacionar o entendimento de Alexandre Libório Dias Pereira que preleciona sobre o comercio eletrônico na atualidade, in verbis: 
[...] traduz-se na negociação realizada por via eletrônica, através do processamento e transmissão eletrônicos de dados, incluindo texto, sons, imagens. Entre tais negociações destacam-se as de bens e serviços, a entrega de linha de conteúdo multimídia, as transferências financeiras eletrônicas, o comércio eletrônico de ações, conhecimento de embarque eletrônico, leilões comerciais, concepção e engenharia em cooperação, contratos públicos, comercialização direta ao consumidor e serviços pós-vendas (LEAL, 2007, p. 13)

Evidentemente que ocorreram transformações no método de negociação e consolidação da aquisição do bem ou serviço por meio da internet, se comparado a sociedade anteriormente formulada sem o advento do acesso à internet. Ou seja, a formalização da compra era realizada por meio físico junto a empresa estabelecida em sua sede comercial física, por meio do qual o consumidor se dirigia fisicamente ao local para a aquisição do bem ou serviço.

Nessa linha com o desenvolvimento tecnológico e com a criação de plataformas on line, os panoramas mudaram de forma radical, implementando um dinamismo, bem como uma facilitação para aquisição de bens ou serviços pelo consumidor.

$\mathrm{Na}$ atualidade o que ocorre é a oferta do bem ou serviço por meio da plataforma eletrônico (sites, Instagram, grupos de venda entre outros) promovendo a troca de dados entre fornecedor e consumidor, com a existência de loja virtual, por conseguinte, possibilitando ao consumidor o acesso a imagem, preço, garantia, funcionamento do produto ou serviço entre outros, e, por fim, o fornecimento de meios de comunicação para interação entre as partes (SAC, contato da plataforma, e-mail).

Consubstanciado nesses requisitos opera-se a estruturação do comercio eletrônico entre as partes fornecedor e consumidor. Nesse sentido, aduz Ricardo Gesteira Ramos de Almeida, in verbis:

(...) entende a necessidade da existência de três requisitos para a caracterização do $e$ commerce: a) oferta constante em uma rede de transmissão e recepção de dados; b) que seja proposta por meio audiovisual, e; c) interatividade entre os negociantes. (ALMEIDA, 2002, p. 88)

Com efeito, em razão da nova estruturação no âmbito digital, abarcando novos conceitos, também é possível se analisar a aplicação da existência da pré-contratação nos meios eletrônicos. Como é cediço a relação pré-contratual entre as partes anterior a consolidação ou formalização contratual, estabelece um dever entre os contratantes, ou seja, o 


\section{QUEBRA DA CONFIANÇA E APLICAÇÃO DA RESPONSABILIDADE CIVIL NAS RELAÇÕES PRÉ- \\ CONTRATUAIS NOS MEIOS ELETRÔNICOS DE NEGOCIAÇÃO}

comportamento manifestado no sentido de pactuar o negócio. Na sociedade virtual tal conduta a ser manifestada entre os contratantes deve ser a mesma existente na pré-contratação física, apenas transferida para ao meio cibernético, com respaldo no artigo 48 do CDC, in verbis:

Art. 48. As declarações de vontade constantes de escritos particulares, recibos e précontratos relativos às relações de consumo vinculam o fornecedor, ensejando inclusive execução específica, nos termos do art. 84 e parágrafos. (g.n.)

Claramente, observa-se, a proteção na fase pré-contratual, inclusive, combinada com a redação do artigo 30 do $\mathrm{CDC}$, que em sua parte final estabelece que integrará as informações veiculadas que vierem a ser celebradas entre partes, in verbis:

Art. 30. Toda informação ou publicidade, suficientemente precisa, veiculada por qualquer forma ou meio de comunicação com relação a produtos e serviços oferecidos ou apresentados, obriga o fornecedor que a fizer veicular ou dela se utilizar e integra o contrato que vier a ser celebrado. (g.n.)

Nessa linha, cumpre colacionar o entendimento de Fabio Ulhôa Coelho:

[...] no comércio eletrônico internáutico, considera-se feita a oferta no momento em que os dados disponibilizados pelo empresário em seu website ingressam no computador do consumidor ou adquirente.

[...] a oferta dá-se no momento em que as informações correspondentes entram no computador do destinatário, ou seja, podem ser processadas por este" (COELHO, 2007, p. 40-41)

Desta forma, a manifestação de ambas as partes nas tratativas das negociações eletrônicas vincula suas condutas para a consolidação do contrato no âmbito virtual. Ressaltase que tal conduta possui validade, inclusive, nas subespécies de comércio eletrônico como $\mathrm{m}$ commerce (mobile-commerce) e t-commerce (smart TV-commerce), ou seja, aquisição de produtos e serviços via celular e smart tv.

Importante salientar que no modelo de negociação virtual a relação de confiança entre as partes é requisito essencial para a consolidação do negócio. Sendo assim, diante do desenrolar das fases de negociação insurge a expectativa legitima das partes na formalização do negócio, principalmente, no viés do contratante/consumidor que espera consolidar a contratação ou compra do bem ou serviço, por meio das informações e comunicações transmitidas pelo fornecedor/contratado.

Por derradeiro, apesar do desenvolvimento tecnológico é plenamente cabível a aplicação dos deveres anexos na relação pré-contratual, os quais vinculam as partes em suas negociações iniciais para formalização do contrato. 


\section{Fases de Negociações}

Nessa unidade do artigo serão abordadas as diferentes fases de negociações dos contratos em geral e eletrônicos em particular, com o intuito de esclarecer as particularidades do instituto e seus reflexos nas relações contratuais comumente estabelecidas na era digital.

\subsection{Das prestações e deveres gerais de conduta das partes e da ruptura abusiva no meio eletrônico}

Nesta fase os comportamentos das partes no desenrolar das tratativas de negociações devem deter importante observação, pois por meio destas, que se formalizará a conclusão do negócio. Tal comportamento é classificado como dever anexo das partes nas relações contratuais, que se operam desde o início das tratativas para consolidação do negócio, bem como no andamento das relações contratuais e no pós-contrato.

Os deveres são intitulados como condutas ou comportamentos que devem ser seguidos pelas as partes para que nenhum dos contratantes venham a causar prejuízo ou dano a outra parte. Aduz Flavio Tartuce e Clóvis do Couto e Silva “o contrato e a obrigação trazem um processo de colaboração entre as partes decorrentes desses deveres anexos ou secundários, que devem ser respeitados pelas partes em todo o curso obrigacional" (TARTUCE, 2013, p.93).

Motivo pelo qual devem ser levados em consideração alguns requisitos essenciais, quais sejam, (i) transparência nas informações, (ii) confidencialidade, (iii) lealdade nas tratativas, (iv) função social do contrato (v) colaboração mutua e a (vi) confiança mutua entre outros.

Cumpre consignar que as tratativas desenvolvidas entre as partes, pode ocasionar a perda de outras oportunidades pela parte interessada/consumidor que possui a legitima expectativa na consolidação das negociações para que o contrato ou negócio venha a ser concretizado.

Nessa linha, o Enunciado 24 do Conselho Superior de Justiça Federal preleciona que “art. 422: em virtude do princípio da boa-fé, positivado no artigo 422 do novo Código Civil, 


\section{QUEBRA DA CONFIANÇA E APLICAÇÃO DA RESPONSABILIDADE CIVIL NAS RELAÇÕES PRÉ- \\ CONTRATUAIS NOS MEIOS ELETRÔNICOS DE NEGOCIAÇÃO}

a violação dos deveres anexos constitui espécie de inadimplemento, independente de culpa", ou seja, a alteração da conduta da parte na fase pré-contratual enseja a responsabilidade.

Conceitua Roberto Senise Lisboa:

(...) a permanência das negociações com a outra parte pode ensejar a perda de outras oportunidades sobre o mesmo assunto, na expectativa de que o contrato venha a ser concluído com aquele que já iniciou as conversações e tratativas prévias ao ajuste. (LISBOA, 2010, p. 213)

Sendo assim, eventual alteração de comportamento da parte, principalmente, no que concerne a conduta do ofertante/fornecedor em desfavor do consumidor pode ensejar responsabilidade pré-contratual. A conduta perpetrada pelo fornecedor é denominada de ruptura abusiva que consiste na quebra contratual ou alteração unilateral não esperada pela outra parte contratante sem fundamentação plausível acarretando o término da relação contratual pactuada. Assim, preleciona Roberto Senise Lisboa:

A responsabilidade pré-contratual não está submetida a eventual cláusula penal ou mesmo outra modalidade de liquidação a forfait, já que inexiste contrato firmado entre as partes. (LISBOA, 2010, p. 213)

Desta forma, caso ocorra alteração de conduta ou ruptura abrupta do contrato pelo fornecedor mesmo que no âmbito eletrônico por meio de tratativas eletrônicas, tal conduta ou ruptura ensejará a responsabilidade pré-contratual passível de indenização.

\subsection{Fase de oferta no âmbito eletrônico}

Nessa linha de raciocínio, no momento da apresentação ou veiculação por meio de publicidade eletrônica junto ao site ou plataforma, abarcando, inclusive, possíveis banners ${ }^{3}$ ou pop ups $^{4}$ veiculados em outros sites que os utilizam como método de propaganda, tal oferta vincula o fornecedor de produtos ou serviços para cumprir o conteúdo disseminado aos possíveis targets que são os consumidores/contratantes.

\footnotetext{
${ }^{3}$ Banners são anúncios inseridos em páginas de web sites, usualmente em locais de alta visibilidade, sendo quase impossível ao usuário não notá-los ao acessar a página que deseja.

${ }^{4}$ Uma janela pop-ups é normalmente pequena e sobrepõe-se à página visitada, como forma de chamar a atenção do usuário para o conteúdo.
} 
Desta forma, cumpre enfatizar que a oferta pública direcionada para concretização da relação de consumo, não possuem apenas um viés simplificado de mero convite, mas uma vinculação da apresentação daquela publicidade ao consumidor que se interesse em adquirir.

Observa-se que tal conduta de vinculação opera efeitos jurídicos perante aquele fornecedor de produtos ou serviços que por meio de sua declaração vontade e intenção de venda se compromete a cumprir o ofertado.

No Código de Defesa do Consumidor, o artigo 30 oferece salvaguarda justamente esta questão, inclusive, enfatizando que publicidade ou informação veiculada em qualquer forma ou meio de comunicação obriga o fornecedor a cumprir o conteúdo transmitido.

Significa dizer que por se tratar de qualquer forma, plenamente cabível a aplicação no âmbito digital, posto que as ferramentas necessárias para veiculação da oferta foram utilizadas nos sites e plataformas eletrônicas possibilitando o acesso ao consumidor. Assim dispõe o artigo 30 do CDC:

Art. 30. Toda informação ou publicidade, suficientemente precisa, veiculada por qualquer forma ou meio de comunicação com relação a produtos e serviços oferecidos ou apresentados, obriga o fornecedor que a fizer veicular ou dela se utilizar e integra o contrato que vier a ser celebrado. (g.n.)

Diante da situação, caso ocorra possível recusa da parte ofertante (fornecedor) em cumprir a oferta apresentada ou publicidade veiculada, o consumidor possui alternativas, a sua livre escolha elencadas no artigo 35 do CDC, para obter o cumprimento daquela oferta exarada. Isto posto, aduz o artigo 35 e seus incisos do CDC, in verbis:

Art. 35. Se o fornecedor de produtos ou servicos recusar cumprimento à oferta, apresentação ou publicidade, o consumidor poderá, alternativamente e à sua livre escolha:

I - exigir o cumprimento forçado da obrigação, nos termos da oferta, apresentação ou publicidade;

II - aceitar outro produto ou prestação de serviço equivalente;

III - rescindir o contrato, com direito à restituição de quantia eventualmente antecipada, monetariamente atualizada, e a perdas e danos. (g.n.)

Sendo assim, preleciona Ana Paula Gamboji Carvalho:

[...] a retirada antecipada e injustificada da oferta terá como consequência não mais a mera sujeição do proponente ao pagamento de perdas e danos, mas a negação de quaisquer efeitos jurídicos à revogação, permanecendo a oferta do fornecedor eficaz 
e o cumprimento da obrigação nela contido obrigatório, salvo outra escolha exercida por parte do consumidor. (LEAL, 2007, p. 111)

Evidente que o não cumprimento da oferta ou publicidade veiculada gerará ao ofertante/fornecedor consequências jurídicas, permanecendo a oferta com eficácia para cumprimento em favor do consumidor, bem como podendo acarretar possível pagamento de perdas e danos.

A discussão que se estabelece é se a mera divulgação por parte do fornecedor de produtos e serviços não seria apenas um simples convite ao consumidor, todavia, cumpre ressaltar que diante da quebra da legitima expectativa suscitada pelo consumidor, em caso de não cumprimento da publicidade veiculada no site ou plataforma, não há como consigna-la como mero convite, posto que a declaração de vontade do fornecedor de produtos e serviços era tornar pública aquela oferta pela via eletrônica para concretiza-la posteriormente com a aceitação do consumidor em adquiri-la. Nesse sentido, aponta Roberto Senise Lisboa:

A oferta ao público, nos termos da legislação protetiva do consumidor, sujeita-se também ao princípio da vinculatividade do ofertante. Entretanto, qualquer pessoa exposta às suas práticas é equiparada ao consumidor, e não somente aquele que se valerá do prazo para expedir aceitação. (LISBOA, 2010, p. 113)

Posto isto, afasta-se a possibilidade de configuração de mero convite, tendo em vista que pode ocorrer possíveis tratativas pré-contratuais no que tange a oferta ou publicidade veiculada para posterior formalização do negócio.

Assim, infere-se que há possibilidade de consignação de oferta eletrônico no âmbito digital, com as suas devidas peculiaridades, vinculando o fornecedor de produtos e serviços a cumprir a publicidade ou oferta veiculada ao consumidor por meio de sites e plataformas on line.

\section{Da aplicação da Teoria da Confiança e da aplicação da Responsabilidade Civil}

Como é cediço no momento da alteração de conduta ou ruptura abusiva do contrato em desfavor do consumidor/contratante ocorre a denominada quebra da legitima expectativa exarada pela parte lesada, que evidentemente suporta prejuízos. O fenômeno da quebra da legitima expectativa é denominado como a violação da teoria da confiança premissa basilar 
para a formalização dos negócios jurídicos, bem como nas relações contratuais pactuados entre os contratantes.

Desta forma, trata-se da legitima expectativa expressada pela parte contratante em relação a conduta do outro contratante/fornecedor nas tratativas iniciais ou na relação contratual que será estabelecida. Cumpre colacionar o entendimento de Claudia Lima Marques no que tange a teoria da confiança:

A manifestação de vontade do consumidor é dada almejando alcançar determinados fins, determinados interesses legítimos. A ação dos fornecedores, a publicidade, a oferta, os contratos firmados criam no consumidor expectativas, também, legítimas de poder alcançar estes efeitos contratuais. (MARQUES, 1999, p. 439)

Isto posto, em razão da era pós-industrial e do desenvolvimento tecnológico as relações contratuais passaram a ser formalizadas no por meio eletrônico. Pode-se afirmar que o interesse social pelas redes digitais, está intrinsecamente ligado as questões de cunho econômico, ou seja, pela expansão do comércio eletrônico que está sendo cada vez mais utilizado pela sociedade.

Com efeito, a teoria da confiança merece detida atenção nos novos métodos de negociações e contratações do âmbito eletrônico, tendo em vista que o consumidor deposita confiança na negociação contratual que se está sendo estabelecida mesmo que de forma eletrônica, por conseguinte, operando-se também a segurança contratual perpetrada no âmbito informacional. Enfatiza Roberto Senise Lisboa:

Mesmo na sociedade da informação em que vivemos, ante a massificação contratual cada vez mais crescente, é possível a identificação de legítima expectativa da conduta da outra parte, desde a oferta até os efeitos posteriores ao término do contrato. (LISBOA, 2010, p.114-115)

Desta forma, o Código de Defesa do Consumidor visa salvaguardar os direitos inerentes a confiança e a segurança contratual exarada pelo consumidor abarcando tanto as relações pré-contratuais, as contratuais e pós-contratais pactuadas por meio da rede. Conforme conceitua Roberto Senise Lisboa:

Tanto os vícios de consentimento como os vícios sociais passaram a ser analisados no novo Código a partir da teoria da confiança, que de forma mais adequada substitui a teoria da responsabilidade tradicional, devendo o operador do direito proceder à verificação da boa-fé objetiva, princípio geral incidente sobre os 


\title{
QUEBRA DA CONFIANÇA E APLICAÇÃO DA RESPONSABILIDADE CIVIL NAS RELAÇÕES PRÉ- CONTRATUAIS NOS MEIOS ELETRÔNICOS DE NEGOCIAÇÃO
}

contratos em geral, deixando-se de lado a boa-fé subjetiva, relegada pelo legislador para os direitos reais. (LISBOA, 2010, p.114-115)

Vale frisar que os mesmos vícios existentes nos contratos físicos ou nos vícios de conduta realizadas pelas partes no âmbito físico, são as mesmas aplicadas ao âmbito digital com as suas devidas especificidades, gerando danos aquele que foi lesado. Prelecionou Liliana Minardi Paesani:

\begin{abstract}
As redes eletrônicas tornaram-se populares com o advento da Internet e a abordagem das implicações que as ligam à responsabilidade civil ainda se mostra incipiente, mas nem por isso deixa de merecer pronta e detida atenção, seja pelo vulto de sua relevância social, seja pelos desafios jurídicos que propõe.

Complementa, ainda, o emaranhado de conexões das redes opera sobre a base da telemática, expressão cunhada na França para designar o cruzamento das telecomunicações com a informática. O resultado é um universo ilimitado de situações próprias da responsabilidade civil, em escala e sofisticação sem precedentes. (PAESANI, 2012, p. 67)
\end{abstract}

Sendo assim, a partir do momento que se concretiza a quebra da legitima expectativa do consumidor por meio da alteração de conduta ou ruptura abrupta das tratativas iniciais pelo fornecedor, acarretando prejuízos ao consumidor/contratante, o fornecedor deverá indenizá-lo. Nessa linha de raciocínio, a violação ao instituto da teoria da confiança gera responsabilidade com detalhes diferenciados da tradicional, principalmente, por se tratar de quebra da legitima expectativa nas relações pré-contratuais. Aduz Roberto Senise Lisboa:

\footnotetext{
O prejuízo porventura causado a um dos negociantes deve ser demonstrado e, como ensina Antônio Chaves, não se configura como um dano contratual. Os danos patrimoniais e extrapatrimoniais porventura existentes geram, pois, a responsabilidade extracontratual daquele que os causou. (LISBOA, 2010, p. 213)
}

Enfatiza-se que a responsabilidade extracontratual, também denominada de Aquiliana, se estabelece da seguinte forma, o agente viola a norma jurídica por meio da prática de um ato ilícito, agindo de forma culposa ou dolosa, causando danos a outrem, como menciona o artigo 186 do Código Civil, assumindo o dever de reparar aquele dano causado, de acordo com artigo 927 do Código Civil.

Nesse sentido, ainda pode ser reivindicado ao causador do dano, o que se denomina de lucros cessantes, do que poderia ser obtido caso o negócio viesse a ser celerado. Conforme Roberto Senise Lisboa: 
Submete-se o causador do prejuízo às perdas e danos, incluindo-se aqui, além dos danos emergentes apurados no processo judicial próprio, os chamados lucros cessantes, isto é, aqueles que a pessoa iria obter caso viesse a celebrar o contrato. A fixação dos lucros cessantes será elevada em razão de eventual frustração em se contratar com outra pessoa porque a vítima tinha legitimamente concluído que contrataria com aquela que, infelizmente, deixou de fazê-lo. (LISBOA, 2010, p. 213)

É incontestável a possibilidade de aplicação do pleito indenizatório pela parte lesada, em virtude da quebra de confiança perpetrada por uma das partes na relação pré-contratual, a qual posteriormente, se consolidaria na formalização da contratação. Nesse sentido é o entendimento de Claudia Lima Marques:

O Princípio da Proteção da Confiança, confiança esta despertada no consumidor pelos produtos e serviços colocados no mercado pela atividade dos fornecedores, exige que se impute, que se responsabilize um maior número de agentes da cadeia de produção, visando à efetiva reparação da vítima/consumidor, como ordena o art. 6. ${ }^{\circ}$, inciso VI do CDC. (MARQUES, 1999, p. 442)

Por fim, é inegável a importância da discussão e análise do tema, tendo em vista os novos meios tecnológicos que possibilitam por meio de plataformas cibernéticas o desenvolvimento do e-commerce entre consumidor e fornecedor. Evidentemente que os consumidores devem ser protegidos utilizando-se de premissas basilares das relações contratuais nos meios eletrônicos, possibilitando que a quebra da legitima expectativa do consumidor mesmo que de forma virtual seja devidamente indenizada.

\section{Considerações Finais}

É inconteste que após as transformações no contexto social, econômico e político pela qual a sociedade passou no ultimo quartil do século $\mathrm{XX}$, em razão da denominada revolução tecnológica, é inquestionável que novas estruturas digitais surgiram facilitando a vida dos indivíduos, inclusive, no que tange ao desdobramento das relações de consumo.

Tal mudança proporcionou novos métodos de negociações e contratações por meio do âmbito digital dinamizando as relações contratuais entre as partes envolvidas, proporcionando, ainda, o desenvolvimento de plataformas eletrônicas que culminaram no comercio eletrônico (e-commerce), abarcando suas subespécies $m$-commerce e t-commerce 


\section{QUEBRA DA CONFIANÇA E APLICAÇÃO DA RESPONSABILIDADE CIVIL NAS RELAÇÕES PRÉ- \\ CONTRATUAIS NOS MEIOS ELETRÔNICOS DE NEGOCIAÇÃO}

mundialmente utilizados, de maneira que paradigmas surgiram e consubstanciaram uma nova realidade.

Nessa linha, analisou-se as relações pré-contratuais consumeristas no âmbito digital por meio do comercio eletrônico modelo B2C (business to consumer) aplicado as plataformas e sites on line que promovem a venda de bens e serviços aos consumidores. Desta forma, em razão da nova estruturação e desenvolvimento comercial via on line, tais procedimentos para venda trazem consigo novos conceitos nas relações de tratativas iniciais relacionadas ao précontrato.

Cumpre enfatizar que o Código de Defesa do Consumidor estabeleceu artigos imperativos e protetivos para salvaguardar direitos dos consumidores, inclusive, na fase précontratual. Vale ressaltar que os deveres gerais de conduta ou também denominados de deveres anexos aos contratos devem ser respeitados pelas partes contratantes, ainda que estejam no âmbito digital por se tratar de premissa basilar vinculadas aos contratos tanto físicos, quanto contratos eletrônicos.

Atrelado a temática a oferta por meio eletrônico possui caráter vinculante do fornecedor em cumprir sua publicidade ou oferta de determinado produto ou serviço, não se tratando de mero convite ao consumidor, mas de oferta vinculativa da exposição do produto ou serviços veiculado nas plataformas on line ou lives promocionais.

Outrossim, o não cumprimento da oferta ou publicidade eletrônica veiculada gerará ao ofertante/fornecedor consequências jurídicas, inclusive, mantendo a oferta com eficácia para cumprimento em favor do consumidor, podendo acarretar em caso de descumprimento pagamento de perdas e danos.

Com efeito, a alteração de conduta ou ruptura abusiva contratual perpetrada pelo fornecedor em face do consumidor/contratante ensejará responsabilidade pré-contratual ainda que no âmbito digital. Nessa linha, ocorrerá também a quebra da legítima expectativa exarada pelo consumidor, o que se denomina como quebra da teoria da confiança premissa basilar no negócio jurídico.

Salienta-se que os mesmos vícios existentes nos contratos físicos ou vícios de condutas realizadas pelas partes de forma física, são as mesmas aplicadas no âmbito digital com a devida analise de suas peculiaridades ao caso em concreto. Sendo assim, diante da conduta do fornecedor e de sua cadeia de fornecedores estes serão responsabilizados ao 
pagamento de indenização para restituir o prejuízo do consumidor ainda que em fase précontratual, por meio da aplicação de responsabilidade extrapatrimonial ou aquiliana.

Ademais, ainda poderá ser reivindicado ao causador do dano o pagamento de lucros cessantes, do que poderia ter sido obtido caso o negócio viesse a ser concretizado.

Assim, compreende-se que a quebra da confiança perante a relação pré-contratual é passível de acolhimento no âmbito digital diante da especificidade do caso, ensejando pagamento a título indenizatório pelo dano causado ao consumidor. Conclui-se que a finalidade almejada por meio da análise da relação pré-contratual nas tratativas inicias para posterior consolidação da contratação no âmbito digital e da vinculação da oferta ou publicidade veiculada pelas plataformas e sites eletrônicos visa demonstrar que as premissas basilares das relações contratuais incluindo os deveres anexos aos contratos devem ser respeitados e observados perante o âmbito virtual.

Motivo pelo qual o descumprimento de tais premissas e princípios ensejam responsabilização passível de pagamento indenizatório ao consumidor lesado, proporcionando ao consumidor segurança jurídica nas relações travadas por meio da internet, não deixando em pune condutas ilícitas por parte dos fornecedores de produtos e serviços em plataformas de $e$-commerce.

\section{Referências}

ALMEIDA, Ricardo Gesteira Ramos de. Aspectos relevantes dos contratos eletrônicos. In: Ivette Senise Ferreira e Luiz Olavo Baptista [coord.]. Novas fronteiras do direito na era digital. São Paulo: Saraiva, 2002.

BARRETO JUNIOR, Irineu Francisco; VENTURI JÚNIOR, Gustavo. Dados pessoais na internet: análise do seu status enquanto mercadoria na sociedade da informação. Anais do $41^{\circ}$. Encontro Anual da ANPOCS. Disponível em: http://www.anpocs.com/index.php/papers-40encontro-2/gt-30/gt02-25/10599-dados-pessoais-na-internet-analise-do-seu-status-enquantomercadoria-na-sociedade-da-informacao/file> Acesso em 10.nov. 2107.

BARRETO JUNIOR, Irineu Francisco. Proteção da Privacidade e de Dados Pessoais na Internet: O Marco Civil da rede examinado com fundamento nas teorias de Zygmunt Bauman e Manuel Castells. In: DE LUCCA, Newton; SIMÃO FILHO, Adalberto; DE LIMA; Cintia Rosa Pereira. (Org.). Direito \& Internet III. São Paulo: Quartier Latin, 2015. p. 100-127. BARRETO JUNIOR, Irineu Francisco; VIGLIAR, José Marcelo Menezes. As funções da jurisprudência na Sociedade da Informação. Rev. Fac. Direito UFMG, Belo Horizonte, n. 73, pp. 391-417, jul./dez. 2018. 
BARRETO JUNIOR, Irineu Francisco; SAMPAIO, Vinícius Garcia Ribeiro; GALLINARO, Fábio. Marco civil da internet e o direito à privacidade na sociedade da informação. Direito, Estado e Sociedade, n.52, p. 114 a 133, jan/jun. 2018.

BRASIL. Legislação. Lei 8.078/1990. Código de Defesa do Consumidor. Disponível em http://www.planalto.gov.br/ccivil_03/Leis/L8078compilado.htm. Acesso em 02.dez.2018.

BRASIL. Legislação. Lei 10.406/2002. Código Civil Brasileiro. Disponível em http://www.planalto.gov.br/ccivil_03/leis/2002/110406.htm. Acesso em 02.dez.2018.

CAVALCANTI; Ana Elizabeth Lapa Wanderley; LEITE, Beatriz Salles Ferreira; BARRETO JUNIOR, Irineu Francisco. Sistemas de Responsabilidade Civil dos provedores de aplicações da internet por ato de terceiros: Brasil, União Europeia e Estados Unidos da América. Revista Eletrônica do Curso de Direito da UFSM, v. 13, n. 2 / 2018 p.506-531.

COELHO, Fábio Ulhoa. Curso de direito comercial: direito de empresa. 7. ed. rev. e atual. São Paulo: Saraiva, 2007.

GUSTIN, Miracy B.S.; DIAS, Maria Teresa Fonseca. (Re)pensando a pesquisa jurídica. 2.ed. ver., ampl. e atual. Belo Horizonte: Del Rey, 2006.

MARQUES, Cláudia L. Contratos no Código de Defesa do Consumidor. 3. ed. Revista atualizada e ampliada, São Paulo: Editora Revista dos Tribunais, 1999.

LEAL, Sheila do Rocio Cercal Santos. Contratos eletrônicos: validade jurídica dos contratos via internet. São Paulo: Atlas, 2007.

LISBOA, Roberto Senise. Manual de Direito Civil: Contratos. vol. 03. 5. ed. São Paulo: Saraiva, 2010.

PAESANI, Liliana Minardi. PAESANI, Liliana Minardi. Direito e Internet: Liberdade de Informação, Privacidade e Responsabilidade Civil. 5. ed. São Paulo: Atlas, 2012.

TARTUCE, Flávio. Direito Civil. Teoria geral dos contratos e contratos em espécie. vol.3. 8.ed., São Paulo: Método, 2013. 